ARQGA / 900

\title{
A IMPORTÂNCIA DA pHMETRIA ESOFÁGICA PROLONGADA NA PESQUISA DO REFLUXO GASTROESOFÁGICO PATOLÓGICO EMCRIANÇAS
}

\author{
Valter Nilton FELIX* e Ricardo Guilherme VIEBIG**
}

RESUMO - Estudos realizados nas duas últimas décadas demonstraram a possibilidade de ter-se com certa freqüência a doença do refluxo gastroesofágico como causa de afecções otorrinolaringológicas ou respiratórias na infância. Ao mesmo tempo, sintomas e sinais como regurgitação freqüente, dor abdominal, retardo de crescimento, entre outros, podem ser originados pela doença do refluxo gastroesofágico em crianças. Os métodos geralmente utilizados para confirmar a presença da doença do refluxo gastroesofágico são a endoscopia, a cintilografia, o estudo radiológico do esôfago e a monitorização prolongada do pH intra-esofágico. Os autores analisam 60 crianças que foram encaminhadas para realizar pHmetria prolongada de esôfago e que tiveram como indicação problemas primariamente digestivos ou respiratórios ou otorrinolaringológicos. Os pacientes foram divididos em dois grupos: o primeiro, constituido por 25 portadores de problemas digestivos e o segundo, de 35 com problemas respiratórios ou otorrinolaringológicos primários. As crianças que tinham problemas relacionados aos dois grupos foram incluidas no primeiro. A pHmetria foi considerada positiva para doença do refluxo gastroesofágico quando os índices de Boix-Ochoa (para 8 meses de idade ou menos) ou de DeMeester (acima de 9 meses) estivessem acima de 11,99 ou 14,72 respectivamente. Foram também comparados os resultados da pHmetria aos achados da endoscopia ou da pesquisa de refluxo por cintilografia em 22 pacientes. Nos pacientes cuja indicação para pHmetria foram manifestações digestivas, houve positividade de 62\%. Já nos com manifestações respiratórias ou otorrinolaringológicas, a positividade foi de 29\%. As crianças que apresentavam manifestações digestivas concomitantes a sintomas respiratórios ou otorrinolaringológicos apresentaram positividade de $66 \%$. Os pacientes que já haviam realizado endoscopia digestiva ou teste cintilográfico apresentaram indices de positividade semelhantes (63\%), independente de terem ou não alterações nestes exames. Pacientes com alterações na endoscopia digestiva ou na cintilografia apresentaram positividade na pHmetria de 37\%. Os autores concluem que a pHmetria esofágica prolongada tem maior chance de estar alterada quando indicada por problemas digestivos em comparação à direcionada por problemas respiratórios/otorrinolaringológicos primários. Endoscopia digestiva alta e pesquisa cintilográfica do refluxo gastroesofágico alteradas não significam pHmetria esofágica prolongada alterada ao mesmo tempo que a pHmetria pode estar alterada mesmo em crianças com endoscopia digestiva alta e pesquisa cintilográfica de refluxo normais. A existência de manifestações digestivas em conjunto com fenômenos respiratórios/ otorrinolaringológicos não aumenta a freqüencia de pHmetria alterada quando comparada à de pacientes com manifestações digestivas exclusivamente.

DESCRITORES - Manometria. Refluxo gastroesofágico. Criança.

* Livre Docente do Departamento de Gastroenterologia da Faculdade de Medicina da Universidade de São Paulo. Diretor Científico do MODINE - Motilidade Digestiva e Neurogastroenterologia, Instituto Brasileiro de Estudos e Pesquisas de Gastroenterologia - IBEPEGE, São Paulo, SP.

** $\quad$ Mestre em Gastroenterologia pelo IBEPEGE. Diretor Técnico do MODINE.

Endereço para correspondência: MODINE - Rua Sílvia, 276 - 01331-010 - São Paulo, SP. 


\section{INTRODUÇÃO}

A anatomia da transição esofagogástrica (TEG) muda com o crescimento do ser humano. Em recém-nascidos há grandes variações anatômicas mas, em geral, os músculos da crura diafragmática são relativamente mais espessos, configurando verdadeiro túnel atravessado pelo esôfago distal. O fundo gástrico e o esôfago distal são fixados por membrana frenoesofágica proeminente. Tanto esta membrana como aquele túnel muscular são bem menos evidentes já nas crianças e menos ainda em adultos, sugerindo efeito maturacional $^{(8)}$.

No feto de 8 semanas, o esôfago abdominal é amplo e longo, como o estômago. Aos poucos vai-se estreitando e encurtando, chegando a ter poucos milímetros no nascimento, depois do qual volta a se alongar, atingindo cerca de $15 \mathrm{~mm}$. Estudos post-mortem de recém-nascidos demonstram espessamento muscular na "área esfincteriana"(4).

Nestes recém-nascidos, no entanto, o esfíncter inferior do esôfago (EIE) é hipotônico ${ }^{(16)}$. Estudos de pré-termos ${ }^{(2)}$ demonstraram que a pressão do EIE é praticamente nula nas primeiras seis semanas após o nascimento. O ganho progressivo de tônus do EIE com a maturação, verificada em estudos experimentais ${ }^{(13,19)}$ deve-se, provavelmente, a sua cada vez maior sensibilidade neurohormonal $^{(10)}$.

BOIX-OCHOA e CANALS ${ }^{(2)}$ atribuem o ganho de pressão do EIE exclusivamente à idade pós-natal, iniciando-se entre 6 e 8 semanas e estendendo-se pelos primeiros 3 meses de vida, fundamentando, inclusive, a naturalidade com que se encara a regurgitação freqüente do conteúdo gástrico dos recémnascidos.

O problema passa a ser diferenciar a "regurgitação fisiológica" do refluxo pato- lógico, que pode determinar esofagite, anemia, estenose esofágica, aspiração broncopulmonar e afecções otorrinolaringológicas severas em crianças.

Cinco fatores são, de há muito ${ }^{(7)}$, listados como fundamentais na contenção do refluxo gastroesofágico (RGE): o segmento intraabdominal do esôfago, o ângulo esofagogástrico, a roseta mucosa da cárdia, a crura diafragmática e a válvula mucosa da TEG.

Modernamente, o "clearance" do refluxo ganhou destaque ${ }^{(13,15)}$, assim como o conceito de relaxamento transitório do $\mathrm{EIE}^{(15)}$, que decorre da distensão gástrica, levando a maior crença em que distúrbios do esvaziamento gástrico possam de fato determinar refluxo severo.

A isto tudo deve-se somar a resistência própria da mucosa esofágica ao refluxo, o componente nociceptivo do esôfago, a qualidade do "clearance" esofágico, dependente da motilidade do órgão e da composição da saliva, o potencial de secreção cloridropéptica do estômago, dependente de outros tantos fatores intervenientes, o refluxo duodenogástrico, variações neurohormonais digestivas, naturais ou patológicas, como outros elementos capazes de interferir no assestamento de doença do refluxo gastroesofágico, uma vez ultrapassados os limites do que se pode conceber como "refluxo fisiológico".

A pHmetria prolongada do esôfago surgiu como método capaz de passar a limpo todas as possibilidades e determinar se há ou não "refluxo patológico" em um determinado indivíduo.

\section{TUTTLE e GROSSMAN ${ }^{(20)}$ descreveram} teste de refluxo ácido usando eletrodo esofágico de $\mathrm{pH}$, com a finalidade de detectar se havia refluxo após instilação de $\mathrm{HCl} 0,1 \mathrm{~N}$ no estômago. Modificações deste teste foram amplamente utilizadas no $\operatorname{Brasil}^{(1,11,18)}$, mas sua limitação é seu caráter exclusivamente momentâneo e qualitativo.

Avaliações quantitativas, muito mais fidedignas, só passaram a ser viáveis a partir do sistema de escores aplicados a medições prolongadas do $\mathrm{pH}$ esofágico ${ }^{(14)}$.

O surgimento dos minieletrodos de vidro permitiu registros de $\mathrm{pH}$ durante 24 horas também em crianças ${ }^{(3)} \mathrm{e}$ finalmente surgiram os registradores portáteis ambulatoriais, os minieletrodos de antimônio, ainda mais suportáveis, e as tabelas e gráficos computadorizados, simplificando de vez o método e tornando-o fundamental para o diagnóstico da doença do refluxo gastroesofágico ${ }^{(15)}$, embora com algumas limitações ${ }^{(5,9)}$.

O reconhecimento de que boa parte das afecções otorrinolaringológicas e pneumológicas de crianças deve-se ao RGE, associado ao caráter prático do exame, tem estendido a sua indicação em pediatria.

Afecções repetidas de vias aéreas superiores e de naso e orofaringe têm levado à realização precoce de pHmetria esofágica prolongada (PEP), pois sua positividade direciona o tratamento de forma correta, evitando repetidas prescrições de antibióticos e antiinflamatórios, sem coibir a real causa da doença.

O objetivo desse estudo é analisar extensa casuística de crianças submetidas a PEP, quando indicada por problemas primariamente digestivos ou respiratórios, observando sua importância na prática clínica.

\section{MATERIAL E MÉTODOS}

\section{Pacientes}

Sessenta crianças, de 3 a 132 meses de idade (média de 32,32 $\pm 25,87$ ) foram submetidas a 
pHmetria esofágica prolongada, no MODINE Motilidade Digestiva e Neurogastroenterologia, Instituto Brasileiro de Estudos e Pesquisas de Gastroenterologia-IBEPEGE, São Paulo, SP., de fevereiro de 1998 a setembro de 1999; 35 tiveram indicação do exame por problemas respiratórios ou otorrinolaringológicos primários (crises asmatiformes, pneumonias, faringites e otites repetidas) e 25 , por problemas digestivos (regurgitações freqüentes, observadas, ou pirose, referida).

\section{Método}

pHmetria prolongada do esôfago

Foi utilizado o registrador móvel Digitrapper Mark III (Synetics Medical Inc.), ao qual foi conectado eletrodo pediátrico de antimônio, de um canal, calibrado antes de cada exame com o uso de soluções de pH 7 e 1.

O eletrodo foi introduzido por uma das narinas e posicionado $3 \mathrm{~cm}$ acima do EIE, nível obtido com a aplicação da fórmula de Strobel: Altura (cm) x 0,252.

Nenhum medicamento bloqueador $\mathrm{H}_{2}$ ou inibidor de bomba protônica foi utilizado nos sete dias precedentes ao exame, de duração mínima de 23 horas, período no qual as crianças permaneceram internadas, para segurança do equipamento, recebendo dieta habitual, mantendo atividades físicas e tendo o diário de refeições e repouso realizado por suas mães.

A alimentação oferecida foi adequada a cada faixa etária por nutricionista e as proibições alimentares restringiram-se a chás, bebidas gasosas e condimentos.

Os dados foram analisados pelo "software" "Esophagogram from Gastrosoft Inc., The Synetics Liberty System", tomando-se os índices propostos por DeMEESTER et al. ${ }^{(6)} \mathrm{e}$ BOIX-OCHOA et al. ${ }^{(3)}$, este para crianças de até 8 meses de idade, respectivamente de pontuação total tida como normal de menos de 14,72 e menos de 11,99, para definição de pHmetria alterada ou não.

\section{Distribuição da casuística}

Problemas digestivos versus problemas respiratórios/otorrinolaringológicos

As crianças foram divididas em dois grupos: o primeiro, de 25 portadoras de problemas digestivos e o segundo, de 35 casos de problemas respiratórios ou otorrinolaringológicos primários. As que tinham problemas relacionados aos dois grupos foram alistadas no primeiro.

Os grupos foram comparados em termos de ocorrência de pHmetria alterada e foram tomados percentuais de positividade do exame em cada um deles.

Outros exames versus pHmetria esofágica prolongada

As 22 crianças que foram submetidas previamente a endoscopia digestiva alta (EDA) e ou pesquisa cintilográfica de RGE (PCR) foram divididas em outros dois grupos: o de crianças que apresentavam resultados normais de tais exames e o de casos que tinham pelo menos um deles compatível com refluxo. Qualquer grau de esofagite foi atribuído a RGE para efeito deste estudo.

Em cada grupo foi verificado o percentual de PEP alterada e os dois foram comparados em termos de positividade do exame.

Associação de problemas digestivos e respiratórios/otorrinolaringológicos

Doze crianças apresentavam, simultaneamente, problemas digestivos e respiratórios/ otorrinolaringológicos. Nelas, foi verificado o percentual de positividade da PEP.

\section{Análise estatística}

Foram utilizados cálculos percentuais e teste $\chi^{2}$, para comparação de grupos, considerando-se o nível de significância 0,05 .

\section{RESULTADOS}

Todos os exames foram realizados sem intercorrências e as análises revelaram:

Problemas digestivos versus problemas respiratórios

A Tabela 1 apresenta resultados concernentes aos dois grupos estudados, em termos de percentuais de PEP alterada, e de comparação entre eles, com a aplicação de teste de $\chi^{2}$.

Nota-se que os grupos são significativamente diferentes entre si; é maior a chance de crianças com problemas digestivos apresentarem pHmetria esofágica prolongada alterada.

Outros exames versus pHmetria esofágica prolongada

A Tabela 2 mostra os percentuais de alteração pHmétrica nos casos de EDA e/ou PCR normais ou compatíveis com refluxo, bem como a comparação entre os grupos, com aplicação de teste $\chi^{2}$.

Observa-se que os grupos são estatisticamente semelhantes. EDA e PCR normais ou alteradas não interferem na chance de se ter pHmetria normal ou alterada.

Associação de problemas digestivos e respiratórios/otorrinolaringológicos

A Tabela 3 revela os percentuais de pHmetria alterada e normal nos casos de tal associação, supostamente devida a RGE. 
Tabela 1 - pHmetria esofágica prolongada em crianças portadoras de problemas digestivos e problemas respiratórios/otorrinolaringológicos

\begin{tabular}{lccc}
\hline & PEP alterada & PEP normal & Total \\
\hline Probl. dig. & $17(68 \%)$ & $8(32 \%)$ & $25(42 \%)$ \\
Probl. resp./ORL & $10(29 \%)$ & $25(71 \%)$ & $35(58 \%)$ \\
Total & $27(45 \%)$ & $33(55 \%)$ & $60(100 \%)$ \\
\hline & $\chi^{2}=9,16$ & $\mathrm{P}<0,05$ &
\end{tabular}

Tabela 2 - Inter-relação entre pHmetria esofágica prolongada e endoscopia digestiva alta/ pesquisa cintilográfica de RGE

\begin{tabular}{lccc}
\hline & PEP alterada & PEP normal & Total \\
\hline EDA e PCR norm. & $5(62 \%)$ & $3(38 \%)$ & 8 \\
EDA e/ou PCR alt. & $9(64 \%)$ & $5(36 \%)$ & 14 \\
Total & $14(63 \%)$ & $8(37 \%)$ & 22 \\
\hline & $\chi^{2}=0,007$ & $P>0,05$ &
\end{tabular}

Tabela 3 - pHmetria esofágica prolongada em crianças com problemas digestivos e respiratórios/otorrinolaringológicos supostamente devidos a refluxo gastroesofágico.

\begin{tabular}{lcc}
\hline & $\mathbf{n}$ & $\mathbf{\%}$ \\
\hline PEP alterada & 8 & 66 \\
PEP normal & 4 & 34 \\
Total & 12 & 100 \\
\hline
\end{tabular}

\section{DISCUSSÃO}

O interesse multidisciplinar sobre os efeitos do RGE tem produzido vários efeitos práticos, entre os quais o reconhecimento das afecções não-esofágicas determinadas pelo refluxo.

Os fenômenos asmatiformes, as pneumonias, faringites e otites repetidas têm sido correlacionadas freqüentemente ao fenômeno, tanto que estes problemas modernamente motivam indicação precoce de pHmetria esofágica prolongada, muitas vezes como primeiro exame a ser realizado na investigação da participação do RGE na gênese daquelas afecções.

Nesta casuística, isto se torna claro, visto $58 \%$ das pHmetrias terem sido solicitadas em decorrência de tais problemas e em somente 22 das 60 crianças estudadas (36\%) terem sido realizadas EDA ou PCR previamente.

Ocorre, no entanto, que apenas $29 \%$ delas revelaram escores compatíveis com PEP alterada (Tabela 1); nas demais, ou o exame falhou, ou de fato a pHmetria foi realizada em crianças de contenção normal do RGE ou de defesa esofágica extremamente eficaz.

Em adultos, sabe-se, nem sempre a pHmetria está alterada mesmo em casos de esofagite de refluxo demonstrada endoscopicamente e são conhecidas suas limitações ${ }^{(9)}$. Nesta casuística tal fato é observado em crianças, pois $36 \%$ dos casos de EDA e/ou PCR alterada(s) apresentam PEP normal (Tabela 2).

Por outro lado, o exame pHmétrico pode ser extremamente útil na detecção do RGE, mesmo com EDA e/ou PCR normal(is) ${ }^{(5)}$ e, nestes casos, os sinais e sintomas extraesofágicos podem ser justificados apesar de não haver doença do refluxo gastroesofágico instalada. Nesta série, isto ocorreu em $62 \%$ de oito crianças.

O EIE é sabidamente hipotônico nos recém-nascidos ${ }^{(16)}$, mas freqüente regurgitação além dos três primeiros meses de vida, principalmente se persistir apesar de prolongada elevação do decúbito após as ingestões, redução do volume alimentar e uso de alimentos mais consistentes, primeiras medidas a serem tomadas no sentido de eliminar ou minimizar o problema, sugere fortemente refluxo patológico.

Daí a eleger a PEP como primeiro exame a ser realizado nestas crianças é um passo, considerando também sua pequena agressividade; de certa forma, tal atitude é justificada nesta série, pois, das 25 crianças cuja indicação do exame baseou-se naquele problema digestivo, associado ou não a pirose, $68 \%$ de fato apresentaram $\mathrm{pHmetria}$ alterada, levando a diferenciação estatística destas crianças, em relação às portadoras de problemas respiratórios/ORL primários, em termos de positividade potencial do exame visto isoladamente.

Nas crianças em que se associam problemas digestivos e respiratórios/ORL, o percentual de PEP alterada é similar, de $66 \%$, o que demonstra que a ocorrência concomitante de manifestações extra-esofágicas não é significativa diante do quadro digestivo.

VANDENPLAS $^{(21)}$ define a PEP como exame de primeira escolha nas crianças com regurgitação freqüente mas, se houver suspeita mais fundamentada de esofagite, inicia a pesquisa diagnóstica com EDA e a pHmetria fica reservada para os casos de esofagite erosiva; caso esteja alterada, são ministrados inibidores de bomba protônica e se for normal, procinéticos. 
Há bastante tempo que, em adultos, os escores pHmétricos, principalmente se apoiados em refluxo combinado, têm servido até como fundamento para indicação de tratamento cirúrgico ${ }^{(15)}$. Em crianças isto não está estabelecido, mas o MODINE tem recebido cada vez maior número de casos pediátricos para controle pós-operatório de tratamento cirúrgico de RGE através de realização de fundoplicatura, provavelmente devido à familiarização de muitos cirurgiões ao método videolaparoscópico, reduzindo a agressividade da operação.

Prognosticar a doença do refluxo ou indicar tratamento cirúrgico em crianças com base exclusivamente em dados pHmétricos, constitui procedimento ao menos temerário.

A indicação hiper-estimada da PEP não provoca grandes danos, pois a série de 60 crianças não demonstrou qualquer efeito indesejável do exame, mas é preciso ter funda- mentação de conceitos para adequada interpretação de seus resultados.

É certo que, quando indicada como primeiro exame para investigação diagnóstica de regurgitação freqüente, se alterada, praticamente descarta a realização de outros exames para confirmação da existência de RGE, mas não detecta complicações.

Por outro lado, a comprovação de refluxo pela PEP não garante que os problemas respiratórios/ORL apresentados pela criança sejam dele decorrentes. Comprovação cintilográfica de aspiração ou prova terapêutica, demonstrando que o tratamento clínico do RGE melhora o quadro extra-esofágico, podem ser de grande valor.

O melhor é incluir a pHmetria em lugar de destaque no arsenal diagnóstico do RGE, mas não prescindir das outras armas disponíveis, procurando preparar-se para usá-las convenientemente, de acordo com a situação.

\section{CONCLUSÕES}

- Quando indicada por regurgitação e/ou pirose, a pHmetria esofágica prolongada tem maior chance de estar alterada, do que quando realizada por problemas respiratórios/ORL primários;

- endoscopia digestiva alta e pesquisa cintilográfica do RGE alteradas não significam $\mathrm{pHmetria}$ esofágica prolongada alterada;

- a pHmetria pode estar alterada mesmo em crianças com endoscopia digestiva alta e pesquisa cintilográfica de refluxo normais;

- a associação de fenômenos respiratórios/ORL à regurgitação e/ou pirose não aumenta a chance de achado de pHmetria alterada, em relação às crianças com problema digestivo exclusivo.

Felix VN, Viebig RG. Esophageal pH monitoring in children with gastroesophageal reflux. Arq Gastroenterol, São Paulo, 36(4):201206, 1999.

ABSTRACT - In the past 20 years the association between gastroesophageal reflux and otorhinolaryngological and/or respiratory afections became more evident by many studies. At the same time it is known that regurgitation, abdominal pain, growth retard, among others signs, could be generated by gastroesophageal reflux in infants, and when these signals are present the suspicious must be considered and they could be referred to perform $\mathrm{pH}$ studies. Sixty children were referred to our center to perform $\mathrm{pH}$ monitoring with gastroesophageal reflux suspicious, with digestive symptoms, respiratory problems or otorhinolaryngological manifestations. The patients were divided in two groups: the first, with 25 children, suffering from digestive manifestations. The second, 35 patients, including otorhinolaryngological or pulmonary symptoms. The children with digestive manifestations and with otorhinolaryngological or pulmonary symptoms were included in the first group. The pH analysis were considered positive for reflux when Boix-Ochoa Index (for 8 months of age or less) or DeMeester index (for 9 months or more) were above 11,99 or 14,72, respectively. The data were also compared to the results of scintigraphic studies for reflux or endoscopic findings in 22 patients. The pH monitoring test were positive in $62 \%$ patients with digestive manifestations. In the group with otorhinolaryngological or pulmonary symptoms the positivity was only 29\%. In the group of children with both afections, the positivity was $66 \%$. In patients that performed scintigraphic test or endoscopy, the pH test positivity were similar, 63\%, without correlation if these other tests were positive or not. Patients with abnormal endoscopy or positive scintigraphic tests for gastroesophageal reflux presented $37 \%$ of positivity in $\mathrm{pH}$ test. We conclude that pH monitoring tests could be altered mainly when referred to investigate digestive manifestations when compared to primary otorhinolaryngological or pulmonary indications. Digestive endoscopy or scintigraphic study altered do not mean positive $\mathrm{pH}$ test and the inverse situation could be find too. Digestive symptoms coexisting with otorhinolaryngological or pulmonary afections do not increase the positivity frequency of the pH tests when compared with digestive manifestations exclusively.

HEADINGS - Manometry. Gastroesophageal reflux. Child. 


\section{REFERÊNCIAS BIBLIOGRÁFICAS}

1. Bettarello A. Estudo motor do esôfago na esclerose sistêmica progressiva. São Paulo 1967. [Tese Livre-Docência - Faculdade de Medicina, Universidade de São Paulo].

2. Boix-Ochoa J, Canals J. Maturation of the lower oesophagus. $\mathbf{J}$ Pediatr Surg, 11:749, 1976.

3. Boix-Ochoa J, Lafuente JM, Gil-Vernet JM. Twenty-four hour esophageal $\mathrm{pH}$ monitoring in gastroesophageal reflux. J Pediatr Surg, 15:74, 1980.

4. Botha GSM. The gastro-esophageal region in infants: observation of the anatomy, with special reference to the closing mechanism and partial thoracic stomach. Arch Dis Child, 33:78, 1958.

5. Cecconello I. pHmetria esofágica prolongada. Arq Gastroenterol, 34:69, 1997.

6. DeMeester TR, Johnson LF, Joseph GJ, Toscano MS, Hall AW, Svinner DB. Patterns of gastroesophageal reflux in health and disease. Ann Surg, 184:459, 1976.

7. Earlan R. Clinical tests of esophageal function. London, Crosby Lockwood Stapler, 1975. p 1-40.

8. Eliska O. Phreno-oesophageal membrane and its role in the development of hiatal hernia. Acta Anat, 86:137, 1973.

9. Felix VN. Análise crítica da pHmetria esofágica. ABCD Arq Bras Cir Dig, 10:61, 1995.

10. Felix VN. Mecanismos intrínsecos da motilidade digestiva. In: Felix VN, Viebig RG, ed. Arquivos de motilidade digestiva e neurogastroenterolgia. S.Paulo, Cop L Print Ed, 1997. p. 1-5.

11. Gama-Rodrigues JJ. Hérnia hiatal por deslizamento. Esofagofundogastropexia associada à hiatoplastia - avaliação clínica, morfológica e funcional. São Paulo, 1974. [Tese - LivreDocência - Faculdade de Medicina, Universidade de São Paulo].
12. Hillemaier AC, Grill BB, McCallum R, Griboski J. Esophageal and gastric motor abnormalities in gastroesophageal reflux during infancy. Gastroenterology, 84:741, 1983.

13. Hillemaier AC, Griboski J, McCallum R, Biancani P. Developmental characteristics of the lower esophageal sphincter in the kitten. Gastroenterology, 89:760, 1985.

14. Johnson LF, DeMeester TR. Twenty-four-hour pHmonitoring of the distal esophagus. A quantitative measure of gastro-oesophageal reflux. Am J Gastroenterol, 62:325, 1974.

15. Johnson LF, DeMeester TR. Developmente of the twenty-fourhour intraoesophageal $\mathrm{pH}$ monitoring computer scoring system. J Clin Gastroenterol, 8(supl.):52, 1986.

16. Kenigsberg K, Aiges H, Alperstein V. A unique device to measure lower esophageal sphincter pressure in unsedated infants. J Pediatr Surg, 16:370, 1981

17. Mittal RK, Holoway RH, Penagrini R, Blackshaw LA, Dent J. Transient lower esophageal sphincter relaxation. Gastroenterology, 109:601, 1995.

18. Pinotti HW. Megaesôfago, motilidade do esôfago e teste de refluxo ácido, antes e após dilatação forçada do cárdia. São Paulo, 1967. [Tese - Livre-Docência - Faculdade de Medicina da Universidade de São Paulo].

19. Spedale SB, Weisbto NW, Morriss JR. Ontogenic studies of gastrointestinal functions. II Lower esophageal sphincter maturation in neonatal beagle puppies. Pediatr Res, 16:851, 1982.

20. Tuttle SG, Grosmann MI. Detection of gastroesophageal reflux by simultaneous measurement of intraluminal pressures and $\mathrm{pH}$. Proc Soc Exp Biol Med, 98:229, 1958.

21. Vandenplas Y. Oesophageal pH monitoring for gastroesophageal reflux in infants and children. Unichester, J.Willey, 1992. 